\title{
The Cranet Survey
}

\section{Improving on a Challenged Research-Practice?}

Christensen, Jesper; Bévort, Frans; Rasmussen, Erling

Document Version

Accepted author manuscript

Published in:

International Studies of Management and Organization

DOI:

10.1080/00208825.2019.1646491

Publication date:

2019

Citation for published version (APA):

Christensen, J., Bévort, F., \& Rasmussen, E. (2019). The Cranet Survey: Improving on a Challenged ResearchPractice? International Studies of Management and Organization, 49(4), 441-464.

https://doi.org/10.1080/00208825.2019.1646491

Link to publication in CBS Research Portal

\section{General rights}

Copyright and moral rights for the publications made accessible in the public portal are retained by the authors and/or other copyright owners and it is a condition of accessing publications that users recognise and abide by the legal requirements associated with these rights.

Take down policy

If you believe that this document breaches copyright please contact us (research.lib@cbs.dk) providing details, and we will remove access to the work immediately and investigate your claim. 


\section{The Cranet Survey: \\ Improving on a Challenged Research-Practice? \\ Jesper Christensen, Frans Bévort, and Erling Rasmussen}

Journal article (Accepted manuscript*)

\section{Please cite this article as:}

Christensen, J., Bévort, F., \& Rasmussen, E. (2019). The Cranet Survey: Improving on a Challenged

Research-Practice? International Studies of Management and Organization, 49(4), 441-464.

https://doi.org/10.1080/00208825.2019.1646491

This is an Accepted Manuscript of an article published by Taylor \& Francis in International Studies of Management and Organization on 21 Aug 2019, available online:

DOI: http://www.tandfonline.com/10.1080/00208825.2019.1646491

* This version of the article has been accepted for publication and undergone full peer review but has not been through the copyediting, typesetting, pagination and proofreading process, which may lead to differences between this version and the publisher's final version AKA Version of Record.

Uploaded to CBS Research Portal: April २०२० 


\title{
The Cranet-survey:
}

\section{improving on a challenged research-practice?}

\author{
$1^{\text {st }}$ revision \\ Submission to Cranet Special Issue on "International \& Comparative HRM" to be published by \\ International Studies of Management \& Organization.
}




\begin{abstract}
The Cranet-survey has mapped HRM-practices for more than 25 years. The time has come to take a closer look at the significance of a unique multinational, longitudinal, empirical endeavor like the Cranet-survey. How may we understand the inner workings and emergent practices of this ambitious research effort in order to better assess the value of the unique data-set and propose avenues for its improvement? This is of course a daunting task if the purpose is to make a general evaluation, as was the case in 2011 in the Human Resource Management Review issue on the Cranet International Network. Rather, the contribution of this paper is to examine the established research practices of the Cranet Network from the point of view of incoming researchers to identify and assess fundamental challenges of design, measurement, and project management that underlie many of the more apparent and often-discussed issues relating to validity, comparability, and the multinational adaptation of standardized research tools. To accomplish this, the paper analyzes the Danish Cranet project from its inception in 1991 until today with particular emphasis on the effort to establish a longitudinally comprehensive Danish database with application in cross-country comparisons, exemplified here through comparisons with New Zealand. On this basis, the paper discusses the ramifications for the Cranet Network and proposes opportunities and potentials for improving future consistency and comparability of the global research practice.
\end{abstract}




\section{INTRODUCTION}

When you approach the Cranet-project, as a new researcher, you cannot help being in awe by the sheer size of the venture both in terms of topical, geographical and temporal scope. It is indeed unique as emphasized by many comparative HRM researchers (e.g. Brewster, Mayrhofer \& Reichel, 2011, Steinmetz et al., 2011). However, there are also doubts as to the relative validity and comparability of such standardized surveys. How much valuable information is actually filtering through all these standardizing procedures, translations and contextually colored interpretations?

Despite these caveats, the data Cranet provides are probably the best source if we want to state something general about how HRM practitioners evaluate HRM practices over time. We honestly recognize the value of a gargantuan effort like the Cranet Project and a way to do this is to showing in practice how the data can be used. We use the comparison of the professionalization of HR in Denmark and New Zealand as an example. As shown, New Zealand is a nation of comparable size and industrial structure (e.g. strong farming tradition, late industrialization), and the Cranet-survey is able to provide us comprehensive information on how the HR-profession in the two countries has evolved comparatively. And it can indeed. In the short analysis we show how the data can support several interesting hypotheses about the professionalization of HRM. However, what happens to our evaluation of the results if we look into the black box of research practice of a project like Cranet as we will do in the following sections of the paper?

When we discuss "research practice" instead of, for instance, "methodology", it is because we accept that what is at issue here is not merely a question about choosing to apply a specific methodology, be it more or less rigorous. "Research practice" is what, through the passing of 
time, grows out of a complex scientific venture like the Cranet project as a result of multiple actions taken by multiple actors inevitably resulting in intended as well as unintended effects. We are not cherishing naïve hopes that this complex organization can be reformed to some sort of fully transparent, orderly and neat operation. On the other hand, we think that it is possible to identify and address some of the variation which stems from this research practice and develop it in a productive way by recognizing its nature openly.

Therefore, we outline the general methodology discussions of comparative longitudinal surveys such as the Cranet-survey. The different concerns of adaptation and standardization are presented to give a general framework with which to discuss the examples of the Cranet-research practice and the paradoxical consequences of measuring differentiation by standardizing the measuring method.

We then analyze examples of the Cranet research practice based on reflections on an established research practice by new Cranet researchers, partly based on our administration of the Danish Cranet survey 2014 and partly on our effort to establish a systematized database. In the process we exemplify the unintended consequences of research practice by showing how these affect an analysis as the Denmark New Zealand compasrison. Furtehermore, we report the challenges encountered and our findings on the consequences of irregularities and unnoticed adjustments when we went deeper into the methodological machinery of the survey. For instance, after working with the data, we found that less than $60 \%$ of the questions remained consistent over two or more recurrent surveys.

Generally, the paper aims to answer three questions. First, what characterizes the Cranet Survey as a research practice? Second, how does the data and research tool match our expectations of methodological rigor? And finally, how is it possible to address problems of 
variance arising from other sources than the data itself without resorting to either unproductive standardization or, on the other hand, complete national autonomy in the design of the survey? In order to answer this, we introduce and analyze the concepts of variance identification and variance distribution to provide an alternative and more implementable solution to the standardization-autonomy trade-off.

\section{Professionalization of HRM in DENMARK AND New ZEALAND}

In the following, we compare and interpret the differences in the historical development and professionalization of HRM in Denmark and New Zealand. After making the case for the comparison, we carry out the analysis of the data. The analysis provides a context for the following discussion of how data are affected by the unintended variance stemming from research practice, affecting the whole objective of longitudinal, comparability, which is critical to the Cranet-survey.

Denmark and New Zealand are in many ways similar: in population size, historical industrial development, openness of the economy and educational aspirations. However, Table 1 also illustrates that there are important differences (Table 1 is based on OECD data (www.data.oecd.org ) accessed on the $8^{\text {th }}$ of January 2016).

\begin{tabular}{|l|r|r|}
\hline & New Zealand & \multicolumn{2}{|l|}{ Denmark } \\
\hline Population & 4.500 .000 & 5.600 .000 \\
\hline Density (capita per km2) & 17 & 133 \\
\hline GDP (per capita US\$) & 38.113 & 46.000 \\
\hline Exports (mil. Us \$ 2014) & 41.948 & 111.726 \\
\hline Exports (\% of GDP) & 29 & 53 \\
\hline Agriculture (\% of exports) & 45 & 19 \\
\hline Tax revenue (US \$ per capita) & 14.676 & 31.054 \\
\hline
\end{tabular}

\footnotetext{
${ }^{1}$ Wikipedia, New Zealand, Denmark, 08-02-2016.
} 


\begin{tabular}{|l|r|r|}
\hline Social spending (\%) & 20,8 & 30,1 \\
\hline Income inequality (Gini) & 0,33 & 0,25 \\
\hline Employment rate (\%) & 74 & 74 \\
\hline Hours worked per Worker & 1.763 & 1.436 \\
\hline Unemployment (\%) & 5,8 & 6,6 \\
\hline Long-term unempl. (\% of unemployed) & 13,6 & 25,2 \\
\hline Self-employment rate (\%) & 15,3 & 9,0 \\
\hline Trade union memb. (\% of employed) 2000 & 22 & 74 \\
\hline Trade union memb. (\% of employed) 2013 & 19 & 67 \\
\hline Internet access (\%) & 80 & 92 \\
\hline Road accidents (per 1 million cap.) & 65 & 34 \\
\hline
\end{tabular}

Table 1. Comparing fundamental societal data on New Zealand and Denmark

Although New Zealand and Denmark are almost antipodes, there are many conspicuous similarities. Historically, both countries have a strong agricultural sector and they have open economies with a high degree of trade with the rest of the world which means they have been exposed to international competition. However, post 1980s changes have put the two countries on different paths, with New Zealand known for its free-market, deregulated approach and Denmark for its extensive welfare state and high taxation regime (Rasmussen \& Lind, 2013). These differences can be detected in terms of internationalization of the economy, composition of exports (New Zealand is still reliant on primary sector exports), spending on social welfare and taxation levels. They have also influenced differences in terms of economic wealth and income inequality. The labour market measures of annual working hours and trade union density are also markedly different.

Thus, changes to economic, social and labour market policies over the last decades have overlaid previous similarities and thus one could argue in favor of both convergence and divergence of the HRM-practice in New Zealand and Denmark. Recently, Capelli (2015) has suggested that the relative criticism and praise of HRM are cyclically and institutionally 
determined and has pointed out how the role of labor market institutions also creates different levels of interest in and focus on HR. For instance, he argues that a lower interest in HRM in US is because interests of US employers are unfettered by unionized labor and government regulation that could balance the interests in the labor market (Capelli, 2015: 60). This is clearly also relevant in respect of New Zealand employers (see Foster et al., 2011, Rasmussen, 2016) and in respect of Danish employers, where the opposite is the case.

The Cranet-data show that the presence of HR-department in organizations in New Zealand is catching up with Danish level in the period from 60.7\% in 1997 to $81.3 \%$ in 2015, while Danish organizations have had a coverage level of between 80-90\% during the entire period (see Table 2). It is interesting to see that before and after the global financial crisis, situations result in approximately $10 \%$ fewer organizations reporting having an HR-department in 2014/2015. This could look like a "shake-out" of HR during the crises in a number of organizations, but overall there is a high coverage of HR-departments in both countries in the period.

Do you have a HR Department? (Table 2)

\begin{tabular}{|c|c|c|c|c|c|c|c|c|c|}
\hline & \multicolumn{8}{|c|}{ Country/Year of Survey } \\
\hline & & $\mathrm{NZ}$ & DK & $\mathrm{NZ}$ & DK & NZ & DK & $\mathrm{NZ}$ & DK \\
\hline & & 1997 & 1999 & 2004 & 2003 & 2011 & 2008 & 2015 & 2014 \\
\hline \multirow{4}{*}{$\begin{array}{l}\text { Do you have an HR } \\
\text { department? }\end{array}$} & \multirow[t]{2}{*}{ No } & 221 & 55 & 71 & 71 & 12 & 29 & 15 & 45 \\
\hline & & $39.3 \%$ & $13,7 \%$ & $24.7 \%$ & $14,2 \%$ & $8.5 \%$ & $8,0 \%$ & $18.8 \%$ & $18,8 \%$ \\
\hline & \multirow[t]{2}{*}{ Yes } & 342 & 626 & 220 & 428 & 129 & 333 & 65 & 193 \\
\hline & & $60.7 \%$ & $85,3 \%$ & $75.3 \%$ & $85,8 \%$ & $90.8 \%$ & $92.0 \%$ & $81.3 \%$ & $81,1 \%$ \\
\hline
\end{tabular}

In Table 3, we get an indication of the size of the investment organizations do in the HRdepartment and specialized HR-activities. Two interesting conclusions spring to mind; while the staffing level in New Zealand remains stable (7 to 9) it seems as if there has been a strong 
growth in Denmark (from 8 to 14) with a minor backslide in 2014. This indicates that even though organizations in New Zealand have had a growing adoption of HR-departments, they do it with a relatively minor investment in manpower. This may be an example of the institutional differences mentioned. As shown above in Table 1, union membership coverage in Denmark is far the most comprehensive, which gives - following the Capelli argument - companies a greater impetus to invest in HR. Another outstanding feature is the 'feminization' of HRM which seems to be strong in both countries. However, the strongest trend is seen in New Zealand (from almost $4 \hat{\delta} / 5$ ㅇ to $1 \delta^{\lambda} / 9$ ) with Danish trend is almost stable (from $2 \hat{\delta} / 5$ ㅇ to $4 \hat{\delta} / 11$ ) . Overall, the data support the general conclusion that, in those organizations who had already established them, HR departments have avoided being scaled back during the global financial crises (Bévort, Larsen, Hjalager og Christensen, 2014).

Total number of people employed in HR department (Mean value)? (Table 3)

\begin{tabular}{|l|r|r|r|r|r|r|r|c|}
\hline \multirow{2}{*}{} & \multicolumn{7}{|c|}{ Country/Year of Survey } \\
\cline { 2 - 9 } & NZ & DK & NZ & DK & NZ & DK & NZ & DK \\
\cline { 2 - 9 } & 1997 & 1999 & 2004 & 2003 & 2011 & 2008 & 2015 & 2014 \\
\hline $\begin{array}{l}\text { Total number of people employed in HR } \\
\text { department }\end{array}$ & 7 & 8 & 7 & 10 & 6 & 18 & 9 & 14 \\
\hline $\begin{array}{l}\text { Total number of male employees in HR } \\
\text { department }\end{array}$ & 4 & 2 & 2 & 4 & 1 & 6 & 1 & 4 \\
\hline $\begin{array}{l}\text { Total number of female employees in HR } \\
\text { department }\end{array}$ & 5 & 5 & 5 & 8 & 5 & 12 & 8 & 11 \\
\hline
\end{tabular}

Another prevalent discussion point within HRM literature is the extent to which the HRexecutive has access to top-management team. As seen from Table 4, it seems again as if New Zealand converges (from a lower level) to the situation in Denmark. While Table 4 shows a rise from $52.5 \%$ in 1999 to $70.2 \%$ in 2014 in Denmark, the New Zealand figures jump from $25.1 \%$ to 
$67.5 \%$. The impression is that New Zealand, concerning a number of parameters within HRM, is following the trend in Denmark with a time lag of 5-10 years.

Does the person responsible for HR have a place on the board or equivalent top executive team? (Table 4)

\begin{tabular}{|c|c|c|c|c|c|c|c|c|c|}
\hline & \multicolumn{8}{|c|}{ Country/Year of Survey } \\
\hline & & $\mathrm{NZ}$ & DK & $\mathrm{NZ}$ & DK & $\mathrm{NZ}$ & DK & $\mathrm{NZ}$ & DK \\
\hline & & 1997 & 1999 & 2004 & 2003 & 2011 & 2008 & 2015 & 2014 \\
\hline \multirow{4}{*}{$\begin{array}{l}\text { Does the person responsible } \\
\text { for HR have a place on the } \\
\text { board or equivalent top } \\
\text { executive team? }\end{array}$} & \multirow[b]{2}{*}{$\mathbf{o}$} & 200 & 220 & 131 & 206 & 40 & 139 & 25 & 70 \\
\hline & & $21.5 \%$ & $57,2 \%$ & $59.8 \%$ & $47,2 \%$ & $29 \%$ & $38,9 \%$ & $31.3 \%$ & $29,8 \%$ \\
\hline & \multirow[b]{2}{*}{ es } & 143 & 243 & 88 & 230 & 98 & 218 & 54 & 165 \\
\hline & & $25.1 \%$ & $52,5 \%$ & $40.2 \%$ & $52,8 \%$ & $71 \%$ & $61,1 \%$ & $67.5 \%$ & $70,2 \%$ \\
\hline
\end{tabular}

Analyzing the professionalization if HRM, one of the important indicators is from where the HR executive is hired. Is experience in the local or another HR department valued or not? Is there an effective labour market for HR-executives/-managers? In Table 5, the background of the person responsible for HR is analyzed by four different sources: internal HR, internal Non-HR, external HR, and external Non-HR. A trend towards professionalization would suggest a higher proportion of managers hired from external HR-departments with internal HR-department as the second choice, as the identity of the profession is becoming stronger. This is based on the observation that, as HR departments have become more widespread and populated by specialists, the stronger the choice the recruiting organization will have and thus it is both more attractive and feasible to hire from external as well as internal HR-departments. On the other hand, there has been a counter-trend in favor of hiring non-HR specialists in order to secure the business focus of the HR department.

In New Zealand the proportion of HR-managers hired from own HR department has doubled from 1997 to 2015 - from $10,7 \%$ to $21,9 \%$ - while the equivalent numbers are $18,3 \%$ to 
13,9\% in Denmark (in 1999 and 2014). When speaking of hiring from external HR-departments, in New Zealand 37\% of HR-executives came from that source in 1997 while in Denmark the percentage was $28.9 \%$ in 1999. In 2015, the proportion in New Zealand was $49.3 \%$ versus $42 \%$ in Denmark. This indicates a relatively stronger trend towards a professional labor market for HR managers in New Zealand than in Denmark. In Denmark, it is generally more likely that the person responsible for $\mathrm{HR}$ is hired from outside the professional HR-specialists.

From where was the person responsible for $\mathrm{HR}$ recruited? (Table 5)

\begin{tabular}{|c|c|c|c|c|c|c|c|c|c|}
\hline & \multicolumn{8}{|c|}{ Country/Year of Survey } \\
\hline & & $\mathrm{NZ}$ & DK & $\mathrm{NZ}$ & DK & $\mathrm{NZ}$ & DK & NZ & DK \\
\hline & & 1997 & 1999 & 2004 & 2003 & 2011 & 2008 & 2015 & 2014 \\
\hline \multirow{8}{*}{$\begin{array}{l}\text { From where } \\
\text { was the } \\
\text { responsible } \\
\text { for HR } \\
\text { recruited? }\end{array}$} & \multirow{2}{*}{$\begin{array}{l}\text { From within the } \\
\text { personnel/ HR } \\
\text { department }\end{array}$} & 55 & 87 & 22 & 60 & 22 & 48 & 16 & 32 \\
\hline & & $10.7 \%$ & $18,3 \%$ & $8.1 \%$ & $14,0 \%$ & $16.1 \%$ & $13,4 \%$ & $21.3 \%$ & $13,9 \%$ \\
\hline & \multirow{2}{*}{$\begin{array}{l}\text { From non- } \\
\text { personnel/ HR } \\
\text { specialists in } \\
\text { your } \\
\text { organization }\end{array}$} & 166 & 179 & 68 & 164 & 19 & 89 & 14 & 72 \\
\hline & & $32.3 \%$ & $37,6 \%$ & $25.1 \%$ & $38,2 \%$ & $13.9 \%$ & $24,9 \%$ & $18.7 \%$ & $31,2 \%$ \\
\hline & \multirow{2}{*}{$\begin{array}{l}\text { From personnel/ } \\
\text { HR specialists } \\
\text { outside of the } \\
\text { organization }\end{array}$} & 190 & 136 & 125 & 137 & 79 & 176 & 37 & 97 \\
\hline & & $37 \%$ & $28,9 \%$ & $46.1 \%$ & $31,9 \%$ & $57.7 \%$ & $49,3 \%$ & $49.3 \%$ & $42,0 \%$ \\
\hline & \multirow{2}{*}{$\begin{array}{l}\text { From non- } \\
\text { personnel HR/ } \\
\text { specialists } \\
\text { outside of the } \\
\text { organization }\end{array}$} & 76 & 74 & 36 & 68 & 17 & 44 & 8 & 30 \\
\hline & & $14.8 \%$ & $15,5 \%$ & $13.3 \%$ & $15,9 \%$ & $12.4 \%$ & $12,3 \%$ & $10.7 \%$ & $13 \%$ \\
\hline
\end{tabular}

Another strong indicator of professionalization is the seniority of the HR manager within the HR profession at the point of inquiry (Table 6). It is quite remarkable that the HR seniority of the HR managers is rising considerably in both countries over the periods we examine. To illustrate we can use how the proportion of HR managers with more than 10 years of HR- 
experience: In New Zealand in 1994 it was 34.9\%, but in 2015 it was $45.3 \%$. In Denmark, it was $25.5 \%$ in 1999 and $63.4 \%$ in 2014 ! The growing proportion indicates that HR careers are becoming more formalized and that many HR specialists stay within the profession when they advance. The number also point to a difference between New Zealand and Denmark, where the HR responsible person tends to have more HR professional seniority in Denmark, which goes along with the earlier observation of New Zealand being in a "runner up" position in terms of professionalization compared to Denmark.

If working in HR, for how long? (in intervals) (Table 6)

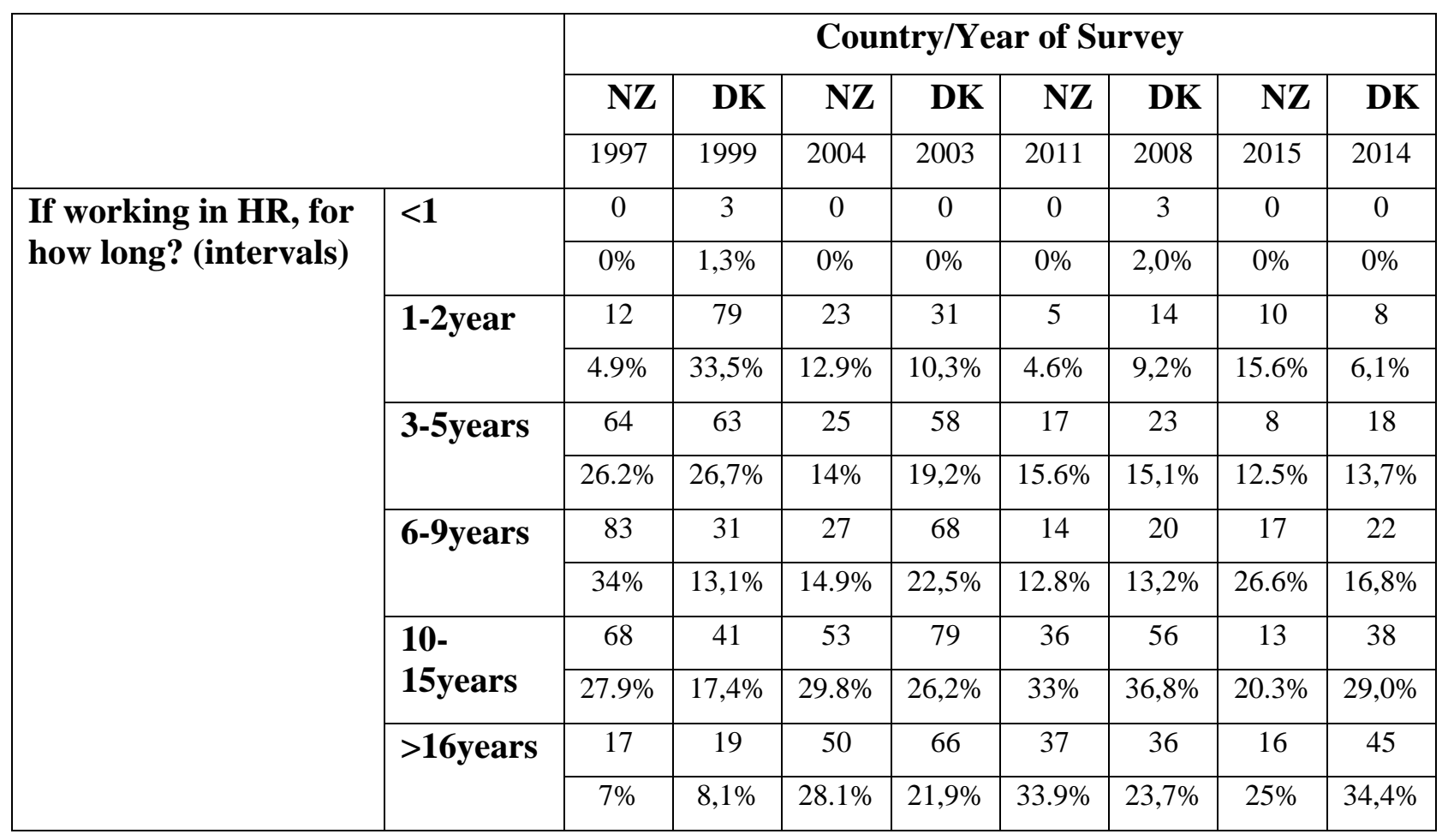

Yet another indicator of professionalization is the level of academic training the HR managers have and the development towards a more sophisticated academic background (Table 7). The numbers show a very parallel development with $52,5 \%$ holding a university degree in New Zealand in 1994 and 56,5\% in Denmark in 1999 and then rising to 75\% (NZ, 2015) and $66,1 \%$ (DK, 2014) respectively. The numbers are not altogether unambiguous, but the general 
trend is from around $50 \%$ to around $70 \%$ with a university degree in the period. Here New Zealand seems to be a bit in front in terms of professionalization.

Do you have a university degree? (Table 7)

\begin{tabular}{|c|c|c|c|c|c|c|c|c|c|}
\hline & \multicolumn{8}{|c|}{ Country/Year of Survey } \\
\hline & & $\mathrm{NZ}$ & DK & $\mathbf{N Z}$ & DK & NZ & DK & NZ & DK \\
\hline & & 1997 & 1999 & 2004 & 2003 & 2011 & 2008 & 2015 & 2014 \\
\hline \multirow{4}{*}{$\begin{array}{l}\text { Do you have a university } \\
\text { degree? }\end{array}$} & \multirow[t]{2}{*}{ No } & 260 & 222 & 95 & 221 & 35 & 88 & 20 & 59 \\
\hline & & $45.6 \%$ & $43,5 \%$ & $34.3 \%$ & $43,7 \%$ & $25.7 \%$ & $26,8 \%$ & $25 \%$ & $33,9 \%$ \\
\hline & \multirow[t]{2}{*}{ Yes } & 299 & 288 & 182 & 285 & 101 & 240 & 60 & 115 \\
\hline & & $52.5 \%$ & $56,5 \%$ & $65.7 \%$ & $56,3 \%$ & $74.3 \%$ & $73,2 \%$ & $75 \%$ & $66,1 \%$ \\
\hline
\end{tabular}

On the surface, this is a very typical and intuitive way of using the Cranet data. We have a set of parameters, which are discussed along the longitudinal perspective and across two nations selected for their apparent similarities. And we do think the analyses appear to make a lot of sense. They indicate how the development of HRM practices converges (in this case the relative professionalization of HR) even in countries situated as antipodes on the globe, albeit with a time lag in the case of New Zealand. The data also seems to lend credence to the institutional hypothesis promoted by Capelli (2015) and many others, that the social institutional context explains a lot of the relative prominence of HR in a specific country (with the difference in unionization between New Zealand and Denmark being very substantial). But our confidence in these interpretations and conclusions changes when we take into account some of what we know about the data collection and generation - and the choices made in that respect.

In the following, therefore, we investigate the influence of the actual research practice of the Cranet Survey on data and interpretations, such as those discussed above. Specifically, we discuss the general problems of comparability in multi-site longitudinal studies and unpack the black box of the realized research practice and its consequences. The ultimate aim is to identify 
sources of unwanted variation and find ways to mitigate them to improve confidence in Cranet results and data.

\section{REVISITING THE COMPARABILITY OBJECTIVE}

Since its inception, the Cranet Survey has been international in outlook and comparative in purpose (Brewster, Hegewisch, and Lockhart, 1991; Brewster et al., 1994). The intention to "[chart] the landscape of human resource management in different socio-cultural contexts and diverse geographical territories" is reflective of a pervasive trend towards comparative international research on management practices and strategy (Parry, Stavrou-Costea, and Morley, 2011: 1; Brewster and Tyson, 1991; Budhwar and Sparrow, 2002). In light of this, Morley (2007) distinguishes three primary trajectories in contemporary HRM research, each encompassing complementary aspects of the internationalization of HRM. One trajectory comprises studies on the role, use, and composition of HRM practices in multinational corporations and in the internationalization of firms in general (e.g. Brewster and Suutari, 2005; Brewster, Wood, and Brookes, 2008; Smale, 2008). A second trajectory employs a more comparative lens to the study of HRM by emphasizing the impact of institutional, economic, and developmental differences on the country-specific adoption and adaptation of HR practices (e.g. Brewster, Larsen, and Trompenaars, 1992; Croucher, Gooderham, and Parry, 2006; FentonO'Creevy, Gooderham, and Nordhaug, 2008). A third trajectory identifies national culture as a prime determinant of idiosyncrasies and similarities in HRM across national and cultural boundaries (e.g. Easterby-Smith, Malina, and Yuan, 1995; Stavrou and Kilaniotis, 2010; Vaiman and Brewster, 2015). Despite their differences, these trajectories indicate a common ambition to identify and trace the evolution of HRM and HR practices within and across countries, 
institutions, and time. Indeed, many studies emerging from the Cranet Survey are not confined to a single trajectory, but rather seek to bridge several perspectives in order to account for and explain the complex interplay of contexts, cultures, and organizational practices (e.g. Brookes et al., 2011; Papalexandris and Panayotopoulou, 2004).

Notwithstanding the trajectories above, any ambition to do comparative and longitudinal research across countries must acknowledge an inherent dilemma (Brewster et al., 1991: 37; Brewster and Tyson, 1991: 8). On one hand, the comparability and validity of cross-national findings rest on the similarity of measurement constructs and the type of information collected. On the other hand, countries and the national features of HRM differ widely in institutional, economic, and cultural respects (Boon et al., 2009; Mayrhofer and Brewster, 2005). Any attempt to standardize data collection will invariably reduce the ability to account for the impact of such idiosyncrasies. As discussed by Lazarova, Morley, and Tyson (2008: 1997), these necessary considerations have given rise to several debates within the HRM and Cranet community about the scope and conceptual delineations of HRM. For instance, the paradigmatic debate on universalist and contextual perspectives in HRM research and debates on national, cultural, and continental differences in HRM have fueled ongoing discussions, especially regarding the evidence for convergence or divergence of practices across countries (Brewster et al., 2007; Gooderham and Brewster, 2008; Mayrhofer et al., 2000; 2011).

On the whole, scholars face a trade-off in comparative HRM research between uncovering and accounting for national differences (a central objective of the Cranet Survey) and ensuring valid and meaningful comparability across countries. In the literature, methodological recommendations have clustered around two strategies for resolving or circumventing the tension: either greater standardization of procedures and constructs or greater survey adaptation 
to national contexts. Indeed, both strategies can be inferred from the prevalent ambition of Cranet scholars "to transcend the cultural differences of the researchers and converge to a standardized procedure of how the study has to be conducted ... [by applying] a common research design ... [consisting of] equivalent measures, that is, measures that are understood by respondents from different countries in the same way" (Steinmetz et al., 2011: 17).

The Cranet Survey reflects these considerations by promoting the adoption of a common research design across countries to foster greater comparability. Thus, each country is expected to adhere to common guidelines in implementation, including the use of a single respondent strategy (Gerhart, 1999; Gerhart, Wright and McMahon, 2000), and a shared and standardized questionnaire that conforms to the ideal of equivalency in constructs and measurement (Hui and Triandis, 1985; Steinmetz et al., 2011). Translation/back-translation is one of the most wellknown methods used in pursuit of common measurements (Brislin, 1970). At the same time, however, recommendations within the Cranet network acknowledge the need to allow for and encourage change and adaptation. At a global level, scholars convene periodically to assess and add to the existing set of questions and themes in order to accommodate trends and novel developments in HRM and in organizations at large (Lazarova et al., 2008). At a local level, the research team is responsible for ensuring fit between the standardized questionnaire and the national context; specifically making sure that questions are understood following translation/back-translation while remaining true to the original intentions. Similarly, the local team has significant autonomy and, hence, responsibility in constructing and maintaining a relevant sampling frame (Häder \& Gabler, 2003; Tregaskis, Mahoney, and Atterbury, 2004), including the crucial balancing act between source triangulation and constraints imposed by resources or institutions. 
We propose that this inherent trade-off between standardization and adaptation strategies is affected by idiosyncrasies in the concrete research practices performed in each country. In order to be able to make deliberate research strategies that take this trade-off into account, we need therefore to explore and understand the impact of local variations, and attempt to identify systematic and predictable patterns in how these variations impact research outcomes.

\section{INSIGHTS FROM THE DANISH CRANET SURVEYS}

Given the raison d'être of the Cranet Survey to generate nationally and temporally comparable HRM data, the schism between adaptation and standardization hints at a range of procedural and definitional challenges that may detract significantly from the validity, comparability, and overall usefulness of the results of the Cranet Survey. Specifically, we explore the development and execution of the Danish Cranet Survey and identify three core issues of design, measurement, and project management that permeate and dictate the quality of the outcomes in the Danish research team over a 25 -year period. We show how insufficient attention to particular elements within these categories, e.g. knowledge retention, sample development, database continuity, institutional impact, and definitional creep, seem to render the higher-level debates on adaptation or standardization moot, as the longitudinal and comparative qualities of the data hinge, at least in part, on a much more basic set of challenges.

Our discussion of these base level elements demonstrates that the relevant decision for Cranet researchers is not in choosing either standardization or country-specific adaptation as their sole strategy. Nor is it feasible to attempt to dissolve the trade-off by imposing singular policies across national research teams, or by allocating significant additional resources to expanding the scope of the survey instrument or the number of researchers involved. Rather, the 
most effective solution to long-term validity lies in proper identification and management of the variations in data that are inevitably produced over time and between countries.

In turn, we argue that communicating and addressing these issues across participant countries is crucial to support the maturation of the Cranet Survey as a research practice in pursuit of its objectives. Building on and providing evidence of the conceptual concerns raised in previous contributions (e.g. Brewster, Mayrhofer and Reichel, 2011; Steinmetz et al., 2011), we contend that a more structured discussion of the identified base elements holds a key to balancing the opposing concerns of standardization and adaptation.

\section{MANAGING LARGE-SCALE LONGITUDINAL RESEARCH EFFORTS}

When any research practice is conducted and maintained across time and space, it becomes a central challenge to organize and manage the interactions among members and their adherence to principles and practices of the organization (Easterby-Smith and Malina, 1999; Geringer, Frayne, and Milliman, 2002; Mayrhofer, 1998), even when organizing is achieved by virtual (Chesbrough and Teece, 1996) or temporary means (Lundin and Soderholm, 1995). Indeed, "managing international research networks over an extended period of time is important for achieving specific kinds of results, in particular country-comparative longitudinal analyses. Yet, the problems linked with it are only rarely addressed in the management literature" (Brewster et al., 2011: 5). One such problem relates to responsibility and the maintenance of procedural insights over time.

At the very foundations of international research networks such as the Cranet Project lies the assumption that knowledge of existing procedures for collecting, structuring, and interpreting data are effectively shared and retained over time within each research unit (the national team) and, indeed, across the international organization in general. Longitudinal comparability within a 
single country, let alone across countries, hinges on the fact that members of the research team are able to effectively share and collectively adhere to similar procedures in data collection and data handling.

While seemingly a basic condition, this cannot be taken for granted. For instance, despite the Danish team being directed by the same senior manager during 1991-2008, the core research team underwent multiple changes in staffing, along with ongoing changes in the distribution of tasks and the involvement of external partners. The main reasons for these changes were staff availability and interest, as team members either became involved in more demanding research tasks elsewhere or developed their academic focus in other directions. And at the same time, the Cranet head office experienced similar changes.

In concert, these changes produced a situation where "knowledge walks out the door" (Beazley, Boenisch, and Harden, 2002: 4; Parise, Cross, and Davenport, 2006), which emphasizes the importance of managing knowledge retention in a research team, let alone in an international research network (e.g. Madsen, Mosakowski, and Zaheer, 2002; 2003). In essence, vital information was not readily available to newcomers in the Danish team. It was exceedingly difficult to retrieve any information as to how the core population of organizations had been determined and how representative samples had been drawn in previous rounds of the survey apart from patchy and ultimately inadequate descriptions of methodology in country reports and associated publications. Relevant documentation and information had vanished with those responsible for the relevant tasks over the years and most of the actual sampling, data collection, and consolidation were undertaken by non-scientific partners with agendas of their own. The changing of the guard in the Cranet head office compounded these issues by making it more difficult to probe the international organization for information and documentation. 
Importantly, the lack of information and relevant insights did not occur over night in the Danish case. Nor is it traceable to one particular instance of neglect or mismanagement. Rather the described situation emerged from a series of gradually accumulating events and decisions that would have seemed reasonable at the time (for example, the inclusion and reliance on nonscientific partners for particular subtasks). Yet, these seemingly minor decisions paved the way for significant challenges in terms of knowledge retention and consistent research practice. As knowledge walked out the door, the seeds were sown for other significant challenges to the consolidation, comparability, and validity of data.

Indeed, as the following sections illustrate, this absence of transparency with respect to both the changes made and the motivations for change has the effect of generating invisible variation across time periods and across countries that is exceedingly difficult for other researchers to identify, reproduce, and account for in later rounds of the survey. Additionally, and with more pernicious effects, the lack of continuity and transparency reduces the ability to gauge the consequences of incremental changes in measurements and sample construction, such as when research teams implement changes to the survey instrument to better reflect new trends or better capture certain phenomena through new measurement scales. When teams are illequipped to understand how elements of the survey tie together, and how they are used differently to either map longitudinal developments, make cross-national comparisons, or simply explore particular phenomena at a single point in time, the team is unlikely to appreciate how seemingly minor changes in phrasing or scaling can reduce the comparability and usefulness of the data for other researchers due to incongruent phrasing or irreconcilable scales.

Based on these observations, we propose that the management of longitudinal research projects such as the Cranet Network should emphasize the dual processes of variance 
identification and variance distribution. Variance identification addresses the issue of invisible variation over time and involves conscious efforts to elucidate and document changes made, as well as clear policies on how to mitigate the effects of unavoidable discontinuities in the research team. This is an effort to create greater transparency and take a more appreciative stance towards inevitable practice based variation, rather than ignoring it or trying to root it out completely. Variance distribution has to do with the unavoidable survey variation between countries and time periods that stems from shifting sampling conditions and changes in measurement. By identifying how individual survey items are different in terms of the objectives to which they mainly contribute ${ }^{2}$, it is possible to describe interdependencies between different clusters of survey items. This mapping provides a decision framework for research teams to better understand the compounding effects of changing one or more items, and to more easily identify ways of distributing the effects of the proposed change by adapting other items in the relevant cluster. In other words, the notion is to exploit overlaps between items to build in a higher level of active robustness and redundancy of information in the survey so as to retain sensitivity to local variation without compromising its general comparability. Both processes are expanded upon in the following sections.

\section{DESIGN CHOICES AND INVISIBLE VARIATION: THE CASE OF BLACK BOX SAMPLING}

Longitudinal survey designs offer a set of distinct advantages over cross-sectional research designs (Tourangeau, 2003). Perhaps the most apparent advantage lies in the ability to identify and estimate within-subject change over time in response to changing conditions or, simply, due to the passage of time (Avey, Luthans, and Mhatre, 2008). Furthermore, by allowing researchers to model time trends independently of other regressors (Wright, 2007), the longitudinal design

\footnotetext{
${ }^{2}$ We distinguish four main objectives (see Table 1). These include comparisons across countries within one time period; longitudinal comparisons within one country; hybrid comparisons of time trends across countries; or simple tests of particular phenomena within one country in one time period.
} 
enables the comparison of within-subject and between-subject changes in the population over time. Such comparisons allow researchers to better determine the extent to which developments in the population are driven by clear changes among few members of the sample or by more moderate changes across larger shares of the population).

To achieve the benefits of longitudinal designs, research teams have to ensure continuity of measurement and consistently representative samples. The importance of proper sample selection for the validity and comparability of survey results is well established in the literature on cross-cultural survey design (Häder and Gabler, 2003; Nasif et al., 1991; Schaffer and Riordan, 2003) and within Cranet methodology (Brewster et al., 2000; Steinmetz et al., 2011). In order to establish and validly test the statistical significance of any proposition, a representative sample must be drawn from the relevant population with a sufficient size to warrant statistical confidence (Fowler, 1993). Barring situations where the entire population can be observed, statistical theory holds that a probability sampling strategy should be pursued in order to confer an equal likelihood of selection of all population members to minimize sampling and nonsampling errors, including non-response bias. However, in the Cranet Survey, as in most other empirical endeavors, practical realities and constraints faced by researchers often lead to "far from ideal standards due to restrictions in time, money or human resources [in which case] applied research has to rely on convenience samples which represent the intended population to an unknown degree" (Steinmetz et al., 2011: 18).

While convenience and non-probability sampling is generally prominent (Bryman, 1989: 113; Denscombe, 2014: 49), it would seem particularly likely in the context of the Cranet Survey considering the difficulties associated with maintaining a sufficiently representative sampling frame of all large organizations, let alone an overview of the full population. Moreover, it has 
been observed that relevant databases of active organizations are often incomplete (Steinmetz et al., 2011). Consequently, the responsibility for selecting among available databases and including other relevant sources to approximate the true population befalls the country representatives (Tregaskis, Mahoney, and Atterbury, 2004). This raises issues of generalizability, sampling error, non-response bias, and attrition (Lillard and Panis, 1998; Hill and Willis, 2001) that will be addressed differently and accounted for to varying degrees in different countries.

In Denmark, the 2014 Survey faced similar challenges. Echoing the lack of knowledge retention and transparent documentation of prior sampling strategies, there were no available records of the company population or associated contact information used in prior rounds. Moreover, it proved impossible to decipher which sampling frame had been used in prior rounds of the survey, let alone the sources used to establish the relevant population, because this information had not been spelled out in sufficient detail in prior publications. As such, the team had to decide, as a first step, whether to survey all companies in the population or to aim for a stratified sample. Given the relatively small size of the population in Denmark, it was deemed relevant to survey the entire sampling frame. Secondly, a sampling frame had to be constructed from available databases and supplemental sources. Sample construction began with the Danish NNE Database ${ }^{3}$, which maintains an overview of key figures, ownership structure, industry, and other relevant information for all public and VAT registered companies in Denmark. The database contained information on approximately 2.200 unique companies and institutions (i.e. excluding subsidiaries and branches) in active operation with more than 100 employees (matching Cranet criteria). Preliminary sorting returned 2.160 relevant companies.

\footnotetext{
${ }^{3}$ Navne \& Numre Erhverv, http://erhverv.nnmarkedsdata.dk/Content/Search/CommonSearch.aspx?focusnews=104
} 
This presented another methodological challenge, however, as the degree to which this sample corresponded to the true population could not be sufficiently ascertained from this source alone. It is important to note that it would have been reasonable to base the survey on the sample, as the database in question was maintained by a dedicated company information provider with the explicit purpose of providing comprehensive data on the population. Hence, the retrieved data would presumably have represented a significant share of the underlying population. Nevertheless, the degree of representation and selection bias remained essentially unknown (cf. Steinmetz et al., 2011), and the team decided to exploit the fact that many complementary sources exist in Denmark. The retrieved list of companies was therefore triangulated with a similar query in the Experian Database, a global business information provider, as well as comparisons with membership information from CBS Executive, an educational institution aimed at senior executives; the Network of Corporate Academies (NOCA), a membership organization focused on bridging research and practice in HRM; and DANSK HR, a networkbased HR-organization for executives and specialists with HRM responsibilities. Triangulation confirmed significant parts of the original list, while other parts were dropped or added, resulting in an ultimate sample of 2.118 companies. In order to counter possible response rate issues and reduce non-response bias, a significant amount of resources had to be invested in finding direct and updated contact information on the director and/or HR responsible individuals in each of the companies in the sample.

Despite our efforts to make our sampling frame as comprehensive as possible to ensure correspondence with prior sampling frames, we were unable to assess the degree to which our actual sample of respondent firms matched prior samples. Although summary statistics from past reports enabled comparisons in terms of industry compositions, firm size, formalization of HR 
practices, and similar aspects, we soon found several discrepancies that were not visible through summary statistics. In the Danish 2008 Cranet survey, for instance, the target population and sampling frame had apparently become mixed up with organization with less than 100 employees, which resulted in a much larger sampling frame compared to the one that was meticulously established in 2014. This effectively prevented us from assessing the comparative qualities of the actual samples, and due to the invisible nature of this variation, we were unable as well to control for these differences without significantly reducing the effective sample size or the number of available variables.

This issue of invisible variation through local adaptation is only compounded across borders. In the New Zealand 2011 Cranet report (Rasmussen \& Ang, 2012), the authors reflect upon changes to the sampling criteria, as the 1997 and 2004 Cranet surveys in New Zealand included organizations with 50 or more employees. In the Cranet format, small countries are allowed to sample below 100 employees so as to generate sufficient responses. However, it was decided in the subsequent surveys, in 2011 and 2015, to use 100 or more employees as the sampling criteria. This decision resides solely with the research team, but the decision of the original New Zealand team to use this threshold has impacted the comparability and validity of the data. For instance, in light of the received wisdom that HR formalization depends on firm size with the threshold for employing a fulltime HR-specialist being around 100 employees, the apparent delay in HR professionalization in New Zealand illustrated in the introduction would be attributable, in part, to the choice to expand the sampling frame with smaller organizations in 1997 and 2004. Additionally, the surveys were administered with time lags of up to three years between the two countries. In relation to the global financial crisis, for instance, this makes a substantial difference, since until 2008 most OECD countries were still growing strongly. In 
2011, the crisis had become evident and consequential in most countries, which is apparent in the Danish 2008 survey. In the four years described in the introduction, the Danish data indicate two opposing trends: a rise in the number of respondents holding a university degree from 2003 to 2008 and an equivalent fall from 2008 to 2014 . This may indicate the influence of the crisis on the professionalization of HR in the two countries (though definite conclusions cannot be obtained before more rounds of the survey have been completed).

Controlling for such alternative cross-national explanations is a tremendous challenge and would reduce effective sample sizes and the number of available variables significantly. Thus, these invisible discrepancies demonstrate the importance of continuous documentation of design decisions, however benign or harmless they may seem in the short run. Specifically, it is necessary for research teams to communicate any deviations from the expected Cranet template on all matters of methodology, be it sampling frame, sample composition, methods of contacting respondent firms, adjustments to national or local limitations (e.g. few large organizations), or post-survey screening of responses, even when these activities have limited value for the present survey. This implies a need for formal support and recognition of the importance of such auxiliary activities to reduce the natural emphasis on the current survey and analyses.

\section{MEASUREMENT ERROR AND VARIANCE DISTRIBUTION}

While longitudinal surveys enable analyses of more expansive effects and an improved mapping of causal relationships compared to cross-sectional designs, they also introduce an additional set of potential measurement errors that need to be accounted for (Das, Toepoel, and van Soest, 2011). The most prominent amongst these is sample attrition (Olson and Witt, 2011; Zabel, 1998), which denotes the tendency for respondents to drop from the sample in subsequent survey rounds. This has obvious implications for the ability to trace changes in time, but it also 
introduces significant bias, as attrition is rarely entirely random (Behr, Bellgardt, and Rendtel, 2005; Olson and Witt, 2011). Rather, attrition depends on respondent characteristics and inclinations (e.g. political/organisational interest correlates with likelihood of completing subsequent surveys), meaning that those who do not attrite are unlikely to be representative of the population (Bartels, 1999; Burden, 2000). And while it is possible to employ statistical imputation or post-stratification weights to partially account for the bias (Henderson, Hillygus, and Tompson, 2010; Kalton and Kasprzyk, 1986), these approaches tend to assume that respondents are missing at random and risk introducing significant bias if this assumption does not hold (Molenberghs et al., 2008).

Other important sources of measurement error in longitudinal research include conditioning effects and seam effects. Conditioning effects refer to the fundamental problem where participation in the survey impacts and conditions responses in subsequent rounds (Lazarsfeld, 1940), either by affecting the motivation and awareness of respondents toward the topic, or by increasing respondent familiarity with the survey instrument (e.g. Kruse et al., 2009). Seam effects refer to the peculiar phenomenon where respondents tend to underestimate change when asked to compare multiple time periods in retrospect, but to overestimate changes when asked at different times (Conrad, Rips, and Fricker, 2009). Whereas the suggestion regarding conditioning effects is to avoid them entirely by proper sampling, as "once they occur the resulting data are irredeemably biased" (Warren and Halpern-Manners, 2012: 522), seam effects may be addressed within the survey by reversing question order or similarly promoting improved respondent reflection and recall (Rips, Conrad, and Fricker, 2003).

What is common to these sources of measurement error is their dependence on respondents. Attrition effects, conditioning effects, and seam effects are all determined, in part, 
by the motivations and autonomous choices of respondents, which puts the effects outside the complete control of researchers. Another source of measurement error that is entirely under the control of researchers, and is therefore perhaps of more relevance to the present discussion, is the composition and design of survey items and associated measurement scales. When these undergo changes, even to relatively minor degrees, the comparison of data across time periods and countries may be compromised if questions are discontinued or merged or if the scaling of questions leads them to become irreconcilable with prior measurements.

To see this, the reader should recall that an explicit purpose for the Danish team was to integrate the results of the 2014 survey with the data from previous years to construct a database capable of supporting the Cranet objective of longitudinal and cross-national comparisons. In light of the above sections, the assumption that this would be a rather straightforward exercise was perhaps naïve. Nevertheless, having adopted the standardized Cranet questionnaire and associated database structure, it was expected that codified data from previous years could be immediately integrated with the present survey to form a longitudinal dataset. In addition, given the push to standardize the questionnaire and data structure throughout the Cranet organization (Lazarova et al., 2008), the data were expected to be easily comparable across countries.

Reflecting the issue of knowledge retention, the first challenge was to simply retrieve the relevant questionnaires and data files. We did not anticipate the fact that some questionnaires were not available in electronic form, but were fortunate enough that they had been stored physically in old archives. Regarding the files, there was no local archive, and the team had no knowledge of whom to ask. It eventually became necessary to contact the central Cranet secretariat in the UK and ask to tap into the central archives. With a diligent secretariat and a bit of luck, it was possible to locate the relevant files in different locations and often in the 
possession of random members (which incidentally shows the strength of the global network).

However, the received files revealed a more daunting problem, as the data had by no means been formatted and labelled consistently over the years. Thus, the second and main challenge in constructing the database was to manually sift through each question from each round of the survey to establish which questions were longitudinally consistent.

We found that inconsistency involved several dimensions. First, questions were not necessarily maintained over time, and many questions had been dropped, merged, or included as adaptations to changing trends or emerging fields of interest. Secondly, even if a question had been retained throughout all surveys, small changes had often crept in over the years, presumably to improve the wording of a particular question or as a by-product of the translation/backtranslation process (Brewster et al., 2011; Brislin, 1970). Third, measurement scales changed over time to different degrees. This ranged from small changes in Likert scale intervals or in the wording of response categories to relatively major shifts in question framing and response categories (e.g. moving from a focus on the presence or absence of a particular phenomenon to asking about the extent of that phenomenon, often in response to particular HR practices becoming more commonplace).

While the exclusion and inclusion of questions has obvious consequences for the longitudinal scope of the survey, changes in the definitions and wording of questions and response categories represent an underlying definitional creep (Strauss, 2001: 886) that proved equally pernicious. Thus, even miniscule changes to the structure or wording of a question can have significant consequences. For example, seemingly irrelevant changes in Likert scale percentage intervals often forced the team to reduce the surveyed information to simple dummy variables measuring the presence or absence of the phenomenon in question, because intervals 
could not be adequately merged or aggregated over time. Similarly, when questions had been changed from a simple yes/no-categorization to a focus on the extent of the given phenomenon (often motivated by a genuine academic interest in mapping the dimensions of the phenomenon), researchers were faced with a trade-off between detail and longitudinal comparability, because comparability could only be maintained by reducing the level of detail to the lowest common denominator (i.e. yes/no).

In essence, the process demonstrated the pervasive and detrimental influence of carelessness in survey implementation, but it also demonstrated the required depth-of-knowledge that the responsible team must possess in order to consciously introduce changes in the survey process, however interesting or academically well-founded they may be. To illustrate the magnitude of this problem, only 57 questions were consistent, or could be made consistent through reduction, across two or more survey rounds (excluding questions that had only appeared in one year). In respect of the questions in the 2014 survey in Denmark, this amounts to an inconsistency share of more than $30 \%$ of the questions that were repeated in two or more survey rounds.

Similar to attrition effects, conditioning effects, and seam effects, the described problems of consistency and measurement add to the total variation across time periods and between countries. While some of this variation is an unwanted by-product of the behavior of respondents, significant parts of it result from well-founded and theoretically relevant changes to the survey instrument. Hence, simply limiting the national teams in terms of their autonomy to adapt and improve upon the instrument is not a feasible solution. Rather, what we observed in our process was that the items that become inconsistent tend to cluster, and that different clusters require different levels of variance distribution. In particular, items in the Cranet survey differ 
with respect to the post-survey questions they are intended to answer. Some are only intended to measure new phenomena of interest in the given period or provide background information to properly control for variation in the present data (e.g. firm characteristics). These measures are robust to adaptation, as they are either limited to one time period or primarily used as auxiliary measures.

On the contrary, items intended for cross-country comparisons in one period or withincountry longitudinal comparisons are far less robust to adaptation and require attention to other measures within the same cluster. As such, we found that many measures in these clusters could be made consistent through combinations with other questions that measured related aspects and thus provided information to bridge the gaps made by prior adjustments. By exploiting these related measures, it is possible to distribute variance using other items to mitigate the detrimental effects of adjustments.

The degree of inconsistency was seen to be particularly severe in items that lend themselves to hybrid analyses with both cross-country and longitudinal elements. Here, even minor adjustments may bias the item on one or both of these dimensions, making it significantly harder to locate relevant information from other questions to attempt to distribute and mitigate variation. Thus, these items require significantly more attention and most likely simultaneous adaptation of related questions to help distribute the resulting variance and mitigate the potential consequences.

We propose that variance distribution is an effective solution to the paradoxical trade-off between standardization and adaptation. While we were fortunate to locate several useful items to base this distribution on in our analyses, the effectiveness of this process would benefit greatly from a more structured approach in national research teams. This would involve a conscious and 
continuous mapping of the interdependencies between items and the emergent clusters and, thereby, provide a kind of scaffolding to enable easier identification of items suited for variance distribution and items that need to be changed in concert with planned adaptations to ensure the possibility of variance distribution in later periods.

\section{DISCUSSION AND CONCLUSIONS}

At first glance, the significance of the above considerations could be rejected simply as procedural errors that could and should be weeded out through professional and conscientious conduct (see Lazarova et al., 2008: 2000). However, while much can undoubtedly be gained through greater adherence to protocol and better application of the survey instrument, significant parts of the variation in the Cranet survey do not result from carelessness, but rather from theoretically relevant change. We argue, therefore, that the usefulness of the Cranet survey may be significantly improved by learning how to accommodate such variance, rather than simply increasing the level of standardization.

We are facing continuous challenges of declining response rates, effects of changing technologies, and an inevitable temporality of the national research teams (Hillygus et al., 2006). As such, our case has highlighted the importance of taking precautions to avoid knowledge walking out the door (Beazley et al., 2002: 4). Despite the ongoing digitalization of scholarly work and our embeddedness within a vast and active network, there is good reason to investigate and implement countermeasures to the inevitable seeping of knowledge.

Importantly, this is not a simple question of safeguarding relevant documents or procedural insights on how the sampling and survey are best conducted. Instead, it has to do with the relevance of establishing and maintaining adequate knowledge of the nature and emergent 
development of the survey instrument to assess the consequences and validity of local adaptations and decisions on implementation strategy. We contend that without this knowledge, adaptations and implementation in general risk becoming haphazard and detrimental to the longitudinal validity of survey results. Indeed, the relevance of this contention is reflected in the discussion of definitional creep and the associated consequences for the quality and comparability of data. Building on this, the Danish survey demonstrates the effects of triangulating several sources of population data on the quality of the sampling frame.

The problem of maintaining a multinational, longitudinal survey has demanded constant convening of Cranet scholars to access and adjust the existing questionnaire to accommodate new developments and trends. The perennial issue of low response rates has also demanded ongoing changes and has likely been in the minds of most national teams as they interpreted findings and issues (see Rasmussen and Ang, 2012: 11). Still, there are other challenges, which have to be overcome in order to secure the credibility of the project in the future. We have shown how complex the organization of such a project is and how much attention to detail and leadership is required to maintain an acceptable data consistency and integrity. There is a huge amount of tacit or implicit knowledge and skill, which must be shared synchronically and diachronically within the organization. In the Danish case, we saw examples of incomplete sharing of knowledge about technical issues and a very patchy accumulation and communication of data and crucial questions between survey rounds. As a result, definitions crept and more than $30 \%$ of the questions became inconsistent and less useful for longitudinal analysis.

There have already been considerable theoretical contributions on related methodological challenges (Brewster et al., 2011; Parry et al., 2011; Steinmetz et al., 2011). This paper points to the micro-research practices in each country as being critical for the quality of data collected, and 
as a potential resolution of the entrenched trade-off between standardization and adaptation. This issue has not been discussed systematically in the literature and provides clear avenues for progress within the Cranet Project. Indeed, we find that that most Cranet member countries approach similar obstacles and struggle with finding the appropriate balance; something that may well be exacerbated by the steadily growing number of members of the Cranet project.

We can do a better job! As such, this paper is partly dedicated to incoming new members or new teams to assist in improving the surveys of the future. Thus, as a complement to the proposed importance of considering and actively engaging in the processes of variance identification and variance distribution, we want to reiterate three basic recommendations with regard to knowledge retention, sample construction, and definitional integrity. Concerning knowledge retention, research teams need to look beyond the survey at hand and their descriptions of current data structures and empirical findings. They need to invest time in describing the deliberations underlying key decisions and prioritizations made in terms of sampling, questionnaire translation and distribution, data consolidation, analysis, and interpretation. While it may seem superfluous to expend resources on documenting these issues, the challenges posed by longitudinal and cross-national analyses call for an improved ability to identify variance by being able to unravel the ongoing methodological deliberations and decisions in order to inform new decisions and explain apparent anomalies in the data and comparisons of results. Teams must acknowledge the path dependency of decisions and refrain from blind dependence on the intrapersonal ability to codify and share relevant procedural learning, which is sufficient in one-off studies but dangerous in longitudinal projects. Moreover, the use of external partners should continue, as it enables greater quality in many instances, but should be accompanied by awareness of the potential impact on knowledge retention of 
outsourcing tasks to non-scientific partners. Lastly, knowledge retention should be underpinned by a structured archive for questionnaires, data files, and other relevant material to support teams down the road.

Regarding sample construction, an important part of a tenable research practice is to thoroughly consider the benefits of engaging in triangulation. The objective of improving the sampling frame prior to undertaking the actual survey should be traded off against the costs of pursuing triangulation, as well as the institutional possibilities of doing so (e.g. the amount and quality of (public) databases and relevant institutional actors from whom to draw relevant company and contact information). It follows that a core element of research practice is the criteria used to assess the adequacy of the sampling frame at hand. As such, it may well be that satisficing is the most feasible strategy for a particular research team if investments in further triangulation are likely to only confirm the extant sample and provide little further value. However, it may be impossible for a research team to reach this conclusion in advance without tapping into the experiences of prior research team members.

Finally, regarding definitional integrity, the key recommendation is to establish and maintain transparency in terms of labelling, formatting, and general data structure across survey rounds. When these criteria are not met, consolidation and analysis require a large effort in terms of reviewing, sorting, and ultimately reducing data from previous years because of uncertainty and inconsistency. In the words of this paper, variance distribution becomes significantly harder to accomplish. To avoid undermining the usefulness of the longitudinal data, research teams must be highly consistent in their terminology and avoid any unnecessary deviations in labelling and measurement. To accomplish this, a consistent and updated database should be maintained to provide a template for the construction and integration of new surveys. In situations when the 
predicted consequences of a proposed change (e.g. decreased comparability or reductions in sample size or measurement specificity) cannot be meaningfully distributed and mitigated through adaptations of related items, the value of the change must be assessed against this backdrop, rather than being assessed only on the theoretical merits of the change.

By becoming more reflexive and experienced in terms of research practice, teams are better positioned to conduct future surveys, as well as predict and assess the consequences of necessary adaptations in the local context. Hence, improving the research practices of teams in each participant country would likely enable a greater flexibility in adapting to and accounting for local variation without compromising the overarching ambition of cross-national and longitudinal comparability. 


\section{REFERENCES}

Avey, J. B., Luthans, F., \& Mhatre, K. H. (2008). A call for longitudinal research in positive organizational behavior. Journal of Organizational Behavior, 29(5): 705-711.

Bartels, L. M. (1999). Panel Effects in the American National Election Studies. Political Analysis, 8: 1-20.

Beazley, H., Boenisch, J., \& Harden, D. (2002). Continuity management: Preserving corporate knowledge and productivity when employees leave John Wiley \& Sons.

Behr, A., Bellgardt, E., \& Rendtel, U. (2005). Extent and determinants of panel attrition in the European Community Household Panel. European Sociological Review, 21(5): 489-512.

Bévort, F., Larsen, H. H., Hjalager, A., \& Christensen, J. (2014). HRM efter krisen. back to square one eller fugl fønix. Copenhagen: Cranet projektet /Academic Books.

Boon, C., Paauwe, J., Boselie, P., \& Den Hartog, D. (2009). Institutional pressures and HRM: developing institutional fit. Personnel Review, 38(5), 492-508.

Brewster, C., \& Tyson, S. (1991). International comparisons in human resource management Financial Times Management.

Brewster, C., Croucher, R., Wood, G., \& Brookes, M. (2007). Collective and individual voice: Convergence in Europe? The International Journal of Human Resource Management, 18(7), 1246-1262.

Brewster, C., Hegewisch, A., \& Lockhart, J. (1991). Researching human resource management: Methodology of the Price Waterhouse Cranfield project on European trends. Personnel Review, 20(6), 36-40.

Brewster, C., Hegewisch, A., Mayne, L., \& Tregaskis, O. (1994). Methodology of the Price Waterhouse Cranfield project. Policy and Practice in European Human Resource Management. London: Routledge, 
Brewster, C., Mayrhofer, W., \& Morley, M. (2000). New challenges for European human resource management Palgrave Macmillan.

Brewster, C., Mayrhofer, W., \& Reichel, A. (2011). Riding the tiger? Going along with Cranet for two decades - A relational perspective. Human Resource Management Review, 21(1), $5-15$.

Brewster, C., Suutari, V., Brewster, C., \& Suutari, V. (2005). Global HRM: Aspects of a research agenda. Personnel Review, 34(1), 5-21.

Brewster, C., Wood, G., \& Brookes, M. (2008). Similarity, isomorphism or duality? recent survey evidence on the human resource management policies of multinational corporations. British Journal of Management, 19(4), 320-342.

Brislin, R. W. (1970). Back-translation for cross-cultural research. Journal of Cross-Cultural Psychology, 1(3), 185-216.

Brookes, M., Croucher, R., Fenton-O'Creevy, M., \& Gooderham, P. (2011). Measuring competing explanations of human resource management practices through the Cranet survey: Cultural versus institutional explanations. Human Resource Management Review, 21(1), 68-79.

Bryman, A. (2003). Research methods and organization studies Routledge.

Budhwar, P. S., \& Sparrow, P. R. (2002). An integrative framework for understanding crossnational human resource management practices. Human Resource Management Review, 12(3), 377-403.

Burden, B. C. (2000). Voter Turnout and the National Election Studies. Political Analysis, 8(4): 389-398.

Capelli, P. (2015). Why we love to hate HR... and what HR can do about it. Harvard Business Review, 93(7-8), 54-61. 
Chesbrough, H. W., \& Teece, D. J. (1996). When is virtual virtuous? Harvard Business Review, 74(1), 65-73.

Conrad, F. G., Rips, L. J., \& Fricker, S. S. (2009). Seam effects in quantitative responses. Journal of Official Statistics, 25(3): 1-24.

Croucher, R., Gooderham, P., \& Parry, E. (2006). The influences on direct communication in British and Danish firms: Country, 'Strategic HRM' or unionization? European Journal of Industrial Relations, 12(3), 267-286.

Das, M., Toepoel, V., \& van Soest, A. (2011). Nonparametric tests of panel conditioning and attrition bias in panel surveys. Sociological Methods \& Research, 40(1), 32-56.

Denscombe, M. (2002). The good research guide: For small-scale social research projects. Idea, $86178035(4)$

Easterby-Smith, M., \& Malina, D. (1999). Cross-cultural collaborative research: Toward reflexivity. Academy of Management Journal, 42(1), 76-86.

Easterby-Smith, M., Malina, D., \& Yuan, L. (1995). How culture-sensitive is HRM? A comparative analysis of practice in Chinese and UK companies. International Journal of Human Resource Management, 6(1), 31-59.

Fenton-O'Creevy, M., Gooderham, P., \& Nordhaug, O. (2008). Human resource management in US subsidiaries in Europe and Australia: Centralisation or autonomy? Journal of International Business Studies, 151-166.

Foster, B., Rasmussen, E., Laird, I. \& Murrie, J. (2011). Supportive legislation, unsupportive employers and collective bargaining in New Zealand. Relations Industrielles/Industrial Relations, 66(2), 192-212.

Fowler Jr, F. J. (2013). Survey research methods Sage publications. 
Geringer, J. M., Frayne, C. A., \& Milliman, J. F. (2002). In search of "best practices" in international human resource management: Research design and methodology. Human Resource Management, 41(1), 5-30.

Gooderham, P. N., \& Brewster, C. (2008). Convergence, stasis or divergence? The case of personnel management in Europe. Current Issues in International Human Resource Management and Strategy Research. München: Rainer Hampp Verlag, 141-156.

Häder, S., \& Gabler, S. (2003). Sampling and estimation. Cross Cultural Survey Methods. Edited by J.Harkness, F.Van De Vijver, and P. Mohler. Wiley.

Henderson, M., Hillygus, D. S., \& Tompson, T. (2010). “Sour grapes” or rational voting? Voter decision making among thwarted primary voters in 2008. Public Opinion Quarterly, 74(3): 499-529.

Hill, D. H., \& Willis, R. J. (2001). Reducing panel attrition: A search for effective policy instruments. Journal of Human Resources, 416-438.

Hillygus, D. S., Nie, N. H., Prewitt, K., \& Pals, H. 2006. The Hard Count: The Political and Social Challenges of Census Mobilization. Russell Sage Foundation.

Kalton, G., \& Kasprzyk, D. (1986). The treatment of missing survey data. Survey Methodology, 12(1): 1-16.

Kruse, Y., Callegaro, M., Dennis, J. M., Subias, S., Lawrence, M., DiSogra, C., \& Tompson, T. (2009). Panel conditioning and attrition in the AP-Yahoo! news election panel study. In 64th conference of the American Association for Public Opinion Research (AAPOR), Hollywood, FL.

Lazarova, M., Morley, M., \& Tyson, S. (2008). International comparative studies in HRM and performance-the Cranet data: Introduction. The International Journal of Human Resource Management, 19(11), 1995-2003.

Lazarsfeld, P. F. (1940). "Panel" Studies. The Public Opinion Quarterly, 4(1): 122-128. 
Lillard, L. A., \& Panis, C. W. (1998). Panel attrition from the Panel Study of Income Dynamics: Household income, marital status, and mortality. Journal of Human Resources, 437-457.

Lundin, R. A., \& Söderholm, A. (1995). A theory of the temporary organization. Scandinavian Journal of Management, 11(4), 437-455.

Madsen, T. L., Mosakowski, E., \& Zaheer, S. (2002). The dynamics of knowledge flows: Human capital mobility, knowledge retention and change. Journal of Knowledge Management, 6(2), 164-176.

Madsen, T. L., Mosakowski, E., \& Zaheer, S. (2003). Knowledge retention and personnel mobility: The nondisruptive effects of inflows of experience. Organization Science, 14(2), 173-191.

Mayrhofer, W. (1998). Between market, bureaucracy and clan: Coordination and control mechanisms in the Cranfield network on European human resource management (Cranet-E). Journal of Managerial Psychology, 13(3/4), 241-258.

Mayrhofer, W., \& Brewster, C. (2005). European human resource management: Researching developments over time. Management Revue, 36-62.

Mayrhofer, W., Brewster, C., Morley, M. J., \& Ledolter, J. (2011). Hearing a different drummer? Convergence of human resource management in Europe-A longitudinal analysis. Human Resource Management Review, 21(1), 50-67.

Molenberghs, G., Beunckens, C., Sotto, C. and Kenward, M. G. (2008). Every missingness not at random model has a missingness at random counterpart with equal fit. J. R. Stat. Soc. Ser. B Stat. Methodol. 70: 371-388.

Morley, M. (2007). Of infants and adolescents: Progress and pessimism in the development trajectory of international human resource management. Keynote Presentation to the 9th IHRM Conference, Tallinn, pp. 12-15. 
Nasif, E. G., Al-Daeaj, H., Ebrahimi, B., \& Thibodeaux, M. S. (1991). Methodological problems in cross-cultural research: An updated review. MIR: Management International Review, 7991.

Olson, K., \& Witt, L. (2011). Are we keeping the people who used to stay? Changes in correlates of panel survey attrition over time. Social Science Research, 40(4): 1037-1050.

Papalexandris, N., \& Panayotopoulou, L. (2004). Exploring the mutual interaction of societal culture and human resource management practices: Evidence from 19 countries. Employee Relations, 26(5), 495-509.

Parise, S., Cross, R., \& Davenport, T. H. (2006). Strategies for preventing a knowledge-loss crisis. MIT Sloan Management Review, 47(4), 31.

Parry, E., Stavrou-Costea, E., \& Morley, M. J. (2011). The Cranet international research network on human resource management in retrospect and prospect. Human Resource Management Review, 21(1), 1-4.

Rasmussen, E \& Ang, A. (2013), Cranet-survey on international strategic human resource management, Report on the New Zealand findings from the 2011-12 survey. Department of management, Auckland University of Management.

Rasmussen, E. \& Lind, J. (2013). In support of a New Zealand 'living wage': reflections on Danish 'working poor' trends and issues. New Zealand Journal of Employment Relations, $38(2), 17-32$.

Rasmussen, E. 2016. A comparative perspective on collective bargaining and the role of employers. In Larsen, T. P. \& Ilsøe, A. (eds.). Den danske model set udefra. FAOS, Copenhagen. (forthcoming)

Rips, L. J., Conrad, F. G., \& Fricker, S. S. (2003). Straightening the seam effect in panel surveys. Public Opinion Quarterly, 67(4): 522-554. 
Schaffer, B. S., \& Riordan, C. M. (2003). A review of cross-cultural methodologies for organizational research: A best-practices approach. Organizational Research Methods, 6(2), 169-215.

Smale, A. (2008). Global HRM integration: A knowledge transfer perspective. Personnel Review, 37(2), 145-164.

Stavrou, E., \& Kilaniotis, C. (2010). Flexible work and turnover: An empirical investigation across cultures. British Journal of Management, 21(2), 541-554.

Steinmetz, H., Schwens, C., Wehner, M., \& Kabst, R. (2011). Conceptual and methodological issues in comparative HRM research: The Cranet project as an example. Human Resource Management Review, 21(1), 16-26.

Strauss, G. (2001). HRM in the USA: Correcting some British impressions. International Journal of Human Resource Management, 12(6), 873-897.

Tourangeau, R. 2003. Recurring Surveys: Issues and Opportunities. National Science Foundation Arlington, VA: Report to the National Science Foundation on a workshop held on March 28-29, 2003.

Tregaskis, O., Mahoney, C., Atterbury, S., Brewster, C., Mayrhofer, W., \& Morley, M. (2004). „International survey methodology: Experiences from the Cranet survey in C. Brewster, W. Mayrhofer, and M. Morley (Ed.),

Vaiman, V., \& Brewster, C. (2015). How far do cultural differences explain the differences between nations? Implications for HRM. The International Journal of Human Resource Management, 26(2), 151-164.

Warren, J. R., \& Halpern-Manners, A. (2012). Panel conditioning in longitudinal social science surveys. Sociological Methods \& Research, 41(4): 491-534. 
Wright, T. A. (2007). A look at two methodological challenges for scholars interested in positive organizational behavior. In D. Nelson, \& C. L. Cooper (Eds.), Positive organizational behavior: Accentuating the positive at work: 177-190. Thousand Oaks, CA: Sage.

Zabel, J. E. (1998). An Analysis of Attrition in the Panel Study of Income Dynamics and the Survey of Income and Program Participation with application to a model of labor market behavior. Journal of Human Resources, 33(2): 479-506. 